\title{
Evaluation of Tourism Developing Level of Yangtze Delta Cities Basing on Analytic Hierarchy Process Analysis and Clustering Analysis
}

\author{
Lin Ma1,2, Chaoqun Yu3 , Yuan Li1,2, Bo Liu'1,2, Bing Liu1,2* \\ ${ }^{1}$ Shandong Provincial Research Center of Landscape Demonstration Engineering Technology for Urban and Rural, Tai'an, China \\ ${ }^{2}$ College of Forestry, Shandong Agricultural University, Tai'an, China \\ ${ }^{3}$ Shandong Urban Construction Vocational College, Jinan, China \\ Email: ^malin@sdau.edu.cn
}

How to cite this paper: Ma, L., Yu, C. Q., Li, Y., Liu, B., \& Liu, B. (2021). Evaluation of Tourism Developing Level of Yangtze Delta Cities Basing on Analytic Hierarchy Process Analysis and Clustering Analysis. Current Urban Studies, 9, 31-39. https://doi.org/10.4236/cus.2021.91003

Received: December 8, 2020

Accepted: February 5, 2021

Published: February 8, 2021

Copyright (C) 2021 by author(s) and Scientific Research Publishing Inc. This work is licensed under the Creative Commons Attribution International License (CC BY 4.0).

http://creativecommons.org/licenses/by/4.0/

\begin{abstract}
Tourism data of 26 cities in the Yangtze River Delta of 2017 are summarized and counted. Method of Analytic Hierarchy Process is used to construct a three-level indicator system, including three secondary indicators such as scale of the tourism industry, number of tourists and tourism income and a number of three-level indicators. And then weight of each indicator is determined, the original data are standardized, and tourism development level score of each city is calculated. Finally, 26 cities are divided into 5 types by cluster analysis and characteristics of each type of cities are analyzed and evaluated.
\end{abstract}

\section{Keywords}

Yangtze Delta Cities, Tourism Development Level, Analytic Hierarchy Process, Cluster Analysis

\section{Introduction}

Yangtze River Delta region is one of the most dynamic, open and innovative regions in China and is an important intersection zone between "Belt and Road" and the Yangtze River economic belt. It plays an important role in the overall situation of national modernization and the all-round opening pattern. As for tourism development, based on rich tourism resources with unique Jiangnan characteristics, modern urban features, historical and cultural heritage, good tour- 
ism services and convenient tourism transportation, this region has become the most attractive and potential tourism economic circle of China (Zhang \& Jia, 2005).

According to the "Development Plan of the Yangtze River Delta Urban Agglomeration" in June 2016 (NDRC, 2016), the Yangtze River Delta urban agglomeration consists of 26 cities concluding Shanghai city and some cities of Jiangsu Province, Zhejiang Province and Anhui Province such as Nanjing, Hangzhou and Hefei, with a land area of 211,700 square kilometers (Figure 1). Because of great differences in tourism resource endowment, infrastructure and social economy, tourism economy development among these cities is uneven (Zhan, 2018). In this study, tourism data of these cities of 2017 were counted and tourism development level of these cities was analyzed and evaluated by analytic hierarchy process and clustering methodology.

\section{Overview of Tourism Development}

In 2017, the total number of visitors in the Yangtze River Delta is 2.06 billion, accounting for $40.2 \%$ of the total number of visitors received of China. The total tourism revenue is 2.97 billion yuan, accounting for $55.8 \%$ of the total tourism revenue of China. By the end of 2017, number of A-grade and above scenic spots, travel agencies and star hotels are separately more than 1370, 6050 and 1520 (MCT, 2018).

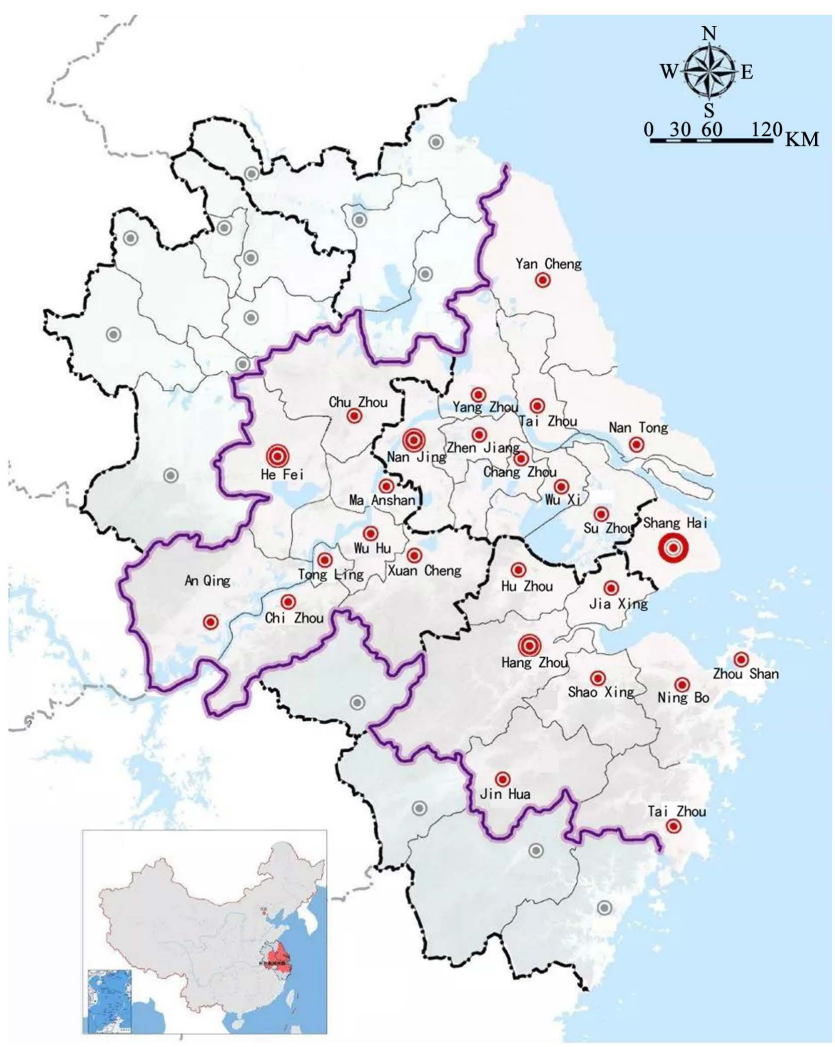

Figure 1. Scope of the Yangtze river delta cities. 


\section{Index System Construction and Evaluation Method}

\subsection{Data Sources}

The data of this paper are from the "China Tourism Yearbook", "China Statistical Yearbook", the economic and social development statistics bulletin and the tourism economic development bulletin of China and each city of the Yangtze River Delta. All of the data are for 2017.

\subsection{Construction of the Index System}

Tourism development level is a comprehensive concept involved with several factors. According to the principles of science, systematicness, comparability and quantitation (Cao et al., 2012), a three-level index system is constructed. The index system is as follows:

A $($ Tourism Development Level $)=($ B1, B2, B3 $)$

In the formula, B1 refers to Tourism Industry Scale including C1 (Number of Star Hotels), C2 (Number of Travel Agencies) and C3 (Number of A-grade and Above Scenic Spots) (Zhang et al., 2013). B2 refers to Tourists Number, including C4 (Domestic Tourists Number) and C5 (Immigration Overnight Tourists Number). B3 refers to Tourism Income, including C6 (Domestic Tourism Income), C7 (Foreign Exchange Income from Tourism) and C8 (GDP Share of Tourism Income).

\subsection{Determination of Index Weights}

The index weight is determined by Analytic Hierarchy Process (Zhu \& Wan, 2005; Liang et al., 2004). The evaluation index judgment matrix is constructed and the evaluation target is assumed to be $A$. The evaluation index set $F=\{f 1$, $f 2, \ldots\}$. The judgment matrix P (A-F) is constructed and then the weight value of each evaluation index is calculated. The calculation result shows that the random consistency ratio of the judgment matrix A is 0.004 (below 0.1) which shows a satisfactory consistency of the hierarchy ranking. The index system and the index weights is shown in Table 1.

\subsection{Standardization of the Data}

To eliminating dimensional or series differences of the index data, all of the data are standardized, the formula is as follows:

$$
Y_{i}=100 * D_{i} / \sum_{i=1}^{n} D_{i}
$$

$Y_{i}$ refers to the dimensionless value after the conversion, $D_{i}$ refers to the index value before the conversion and $\sum_{i=1}^{n} D_{i}$ refers to the sum of all of the evaluation
indexes.

\subsection{Calculation of the Development Level Score}

Combined with the weights, the standardized scores of each index are summed. 
Table 1. Index system of tourism development level of Yangtze delta cities.

\begin{tabular}{|c|c|c|c|c|}
\hline Goal & Structure & Weight & Detailed indicator & Weight \\
\hline \multirow{8}{*}{$\begin{array}{c}\text { A } \\
\text { Tourism } \\
\text { Development } \\
\text { Level }\end{array}$} & & \multirow{3}{*}{0.3011} & C1 Number of Star Hotels & 0.0874 \\
\hline & $\begin{array}{c}\text { B1 } \\
\text { Tourism }\end{array}$ & & C2 Number of Travel Agencies & 0.0625 \\
\hline & Industry Scale & & $\begin{array}{l}\text { C3 Number of A-grade and } \\
\text { Above Scenic Spots }\end{array}$ & 0.1512 \\
\hline & & \multirow[b]{2}{*}{0.3439} & C4 Domestic Tourists Number & 0.1824 \\
\hline & $\begin{array}{c}\text { B2 } \\
\text { Tourists Number }\end{array}$ & & $\begin{array}{l}\text { C5 Immigration Overnight } \\
\text { Tourists Number }\end{array}$ & 0.1615 \\
\hline & \multirow{3}{*}{$\begin{array}{c}\text { B3 } \\
\text { Tourism Income }\end{array}$} & \multirow{3}{*}{0.3550} & C6 Domestic Tourism Income & 0.1416 \\
\hline & & & $\begin{array}{l}\text { C7 Foreign Exchange Income } \\
\text { From Tourism }\end{array}$ & 0.1520 \\
\hline & & & C8 GDP Share of Tourism Income & 0.0614 \\
\hline
\end{tabular}

The formula is as follows:

$$
Y=\sum_{i=1}^{n} W_{i} X_{i}
$$

$Y$ refers to the score value of A (Tourism Development Level), $W_{i}$ refers to the weight of the $i$ index, $X_{i}$ refers to the evaluation score of the $i$ index, and $n$ refers to the number of the evaluation indexes.

\subsection{Cluster Analysis}

Cluster analysis is mainly used to identify similar things and classify them according to their different characteristics, so that the same kind of things has a high degree of similarity. By using software of Statistic Package for Social Science, the cluster analysis of Yangtze River Delta cities is carried out according to above tourism indexes, and the clustering is carried out strictly by the Schwarz Bayesian criterion.

\section{Results and Analysis}

\subsection{Tourism Development Level Score}

According to the tourism statistics of each city of the Yangtze River Delta of 2017, the tourism development level of each city is calculated according to above evaluation index system (Table 2), and the tourism development level of each city is analyzed.

It can be seen from Table 2 that the tourism development level of Shanghai is 20.02 , which is much higher than that of the other 25 cities. Cities with higher economic development level, such as Hangzhou, Suzhou, Nanjing and Ningbo, whose tourism development level score is also higher. Except of Hefei, the level of tourism development of Anhui Province is generally low (less than 2.60). Overall, the level of tourism development of Shanghai, Jiangsu Province and Zhejiang Province is significantly higher than that of Anhui Province. 
Table 2. Scores of tourism development level of Yangtze delta cities.

\begin{tabular}{|c|c|c|c|c|c|}
\hline & $\begin{array}{l}\text { B1 Tourism } \\
\text { Industry Scale }\end{array}$ & $\begin{array}{l}\text { B2 Tourists } \\
\text { number }\end{array}$ & $\begin{array}{l}\text { B3 Tourism } \\
\text { income }\end{array}$ & $\begin{array}{c}\text { A Tourism } \\
\text { Development Level }\end{array}$ & Ranking \\
\hline Shanghai & 4.03 & 8.47 & 7.52 & 20.02 & 1 \\
\hline Hangzhou & 2.62 & 3.99 & 4.48 & 11.08 & 2 \\
\hline Suzhou & 1.68 & 2.22 & 3.08 & 6.97 & 3 \\
\hline Nanjing & 1.70 & 1.54 & 1.95 & 5.19 & 4 \\
\hline Ningbo & 1.65 & 1.30 & 1.08 & 4.03 & 5 \\
\hline Huzhou & 1.04 & 1.61 & 1.36 & 4.02 & 6 \\
\hline Jinhua & 0.78 & 1.62 & 1.37 & 3.76 & 7 \\
\hline Hefei & 0.97 & 1.28 & 1.28 & 3.53 & 8 \\
\hline Wuxi & 0.94 & 1.13 & 1.44 & 3.52 & 9 \\
\hline Jiaxing & 1.19 & 1.27 & 1.04 & 3.50 & 10 \\
\hline Shaoxing & 1.28 & 1.26 & 0.89 & 3.43 & 11 \\
\hline Yangzhou & 1.22 & 1.23 & 0.85 & 3.30 & 12 \\
\hline Zhenjiang & 1.16 & 1.30 & 0.72 & 3.18 & 13 \\
\hline Taizhou & 1.16 & 1.04 & 0.93 & 3.13 & 14 \\
\hline Changzhou & 1.42 & 0.70 & 0.79 & 2.90 & 15 \\
\hline Zhoushan & 0.65 & 0.70 & 1.24 & 2.60 & 16 \\
\hline Chizhou & 0.68 & 0.72 & 1.20 & 2.60 & 17 \\
\hline Anqing & 1.01 & 0.70 & 0.82 & 2.53 & 18 \\
\hline Nantong & 1.16 & 0.49 & 0.52 & 2.17 & 19 \\
\hline Wuhu & 0.60 & 0.69 & 0.71 & 2.00 & 20 \\
\hline Xuancheng & 0.91 & 0.41 & 0.45 & 1.77 & 21 \\
\hline Yancheng & 0.94 & 0.29 & 0.30 & 1.53 & 22 \\
\hline Taizhou & 0.82 & 0.25 & 0.28 & 1.35 & 23 \\
\hline Ma anshan & 0.46 & 0.35 & 0.38 & 1.19 & 24 \\
\hline Chuzhou & 0.50 & 0.29 & 0.27 & 1.06 & 25 \\
\hline Tongling & 0.33 & 0.20 & 0.23 & 0.76 & 26 \\
\hline
\end{tabular}

\subsection{Cluster Analysis Results}

According to the clustering results, the 26 cities of the Yangtze River Delta are divided into 5 levels, as shown in Table 3.

\subsection{Results Analysis}

The characteristics of tourism development of the five types cities are analyzed as follows.

1) The 1st level-Type of tourism metropolitan

Shanghai, as one of the largest cities and economic centers of China, of which 
Table 3. Clustering results of tourism developing level of Yangtze delta cities.

\begin{tabular}{cccc}
\hline Levels & Cities & $\begin{array}{c}\text { The } \\
\text { average } \\
\text { score }\end{array}$ & $\begin{array}{c}\text { Evaluation of } \\
\text { tourism } \\
\text { development level }\end{array}$ \\
\hline 1 & Shanghai & 24.76 & Excellent \\
3 & Hangzhou, Suzhou, Nanjing & 7.75 & Better \\
& Ningbo, Huzhou, Jinhua, Hefei, Wuxi, Jiaxing & 3.73 & Good \\
4 & $\begin{array}{c}\text { Shaoxing, Yangzhou, Zhenjiang, Taizhou, } \\
\text { Changzhou, Zhoushan, Chizhou }\end{array}$ & 3.02 & Intermediate \\
& $\begin{array}{c}\text { Anqing, Nantong, Wuhu, Xuancheng, Yancheng, } \\
\text { Taizhou, Ma anshan, Chuzhou, Tongling }\end{array}$ & 1.59 & Worse \\
\hline
\end{tabular}

the economic development level, the science and education culture level and the tourism development level in the Yangtze River Delta region is second to none. The total tourism income of Shanghai in 2017 is 449.5 billion yuan, accounting for $15.16 \%$ of the total tourism income of the Yangtze River Delta region. Shanghai received 327.18 million domestic and foreign tourists, accounting for $15.91 \%$ of the total number of tourists received in the Yangtze River Delta region. The tourism development score is 20.02, far higher than the score of 11.08 of the second city Hangzhou. The number of A-grade scenic spots, star hotels and travel agencies and other tourism indexes are also extremely prominent. All these data fully show that Shanghai plays a leading role in the Yangtze River Delta and is one of the most important center of China's tourism (He, 2013).

2) The 2nd level-Type of regional tourism center

Hangzhou and Nanjing, separately as the provincial capitals of Zhejiang Province and Jiangsu Province, with super natural and geographical conditions, of which the richness of tourism resources and the perfection of tourism facilities are superior to other cities. As the regional tourism centers, both of them rank the first batch of the "National Historical and Cultural City", the first batch of the "National Excellent Tourist City", the "National Garden City", and the "National Hygienic City".

By the end of 2017, there are 89 A-grade scenic spots in Hangzhou including 4A and above scenic spot such as West Lake, Song Dynasty City, Qiandao Lake, Tianmu Mountain and so on. There are 162.86 million domestic and foreign tourists received by Hangzhou in 2017 and the total tourism income is 304.1 billion yuan. Hangzhou is honored with "International Garden City", "China’s Best Tourist City", "National Health City" and so on.

There are 53 A-grade scenic spots in Nanjing including 4A and above scenic spot such as Sun Yat-sen Mausoleum, Ming Xiao Mausoleum, Presidential Palace, Xuanwu Lake Park and so on. The number of travel agencies and star hotels is 624 and 83 . There are 122.93 million domestic and foreign tourists received by Nanjing and the total tourism income is 216.9 billion yuan, accounting for $18.51 \%$ of GDP. All of these fully illustrated importance of tourism in Nanjing's 
social and economic development.

Although Suzhou is not the capital city, with its strong economic strength (GDP17300 billion yuan, next to Shanghai), unique tourist resources (62 A-grade scenic spots) and excellent tourist facilities (104 star hotels, 387 domestic and foreign travel agencies), the tourism development score is 6.97 and the total tourism income is 232.7 billion yuan, both of which are higher than Nanjing.

3) The 3rd level-Type of regional tourism sub-center

The economy structure, infrastructure, science and education, tourism resources and environmental conditions of cities such as Ningbo, Huzhou, Jinhua and Jiaxing of Zhejiang Province, Wuxi of Jiangsu Province and Hefei of Anhui Province are well. The total tourism incomes of these cities are among 102.609 billion yuan to 174.366 billion yuan. Wuxi's tourism income is the highest (174.366 billion yuan) and the next is Ningbo (171.595 billion yuan). The tourism development level of these cities is between 3.50 and 4.03 and the average score is 3.73. Although the economy aggregate of Huzhou is low, its total tourism income is 110.49 billion yuan and the total tourism income accounts for $44.62 \%$ of GDP which related to its unique location advantage and rich tourism resources.

4) The 4th level-Intermediate type of tourism development

Cities such as Shaoxing, Taizhou and Zhoushan of Zhejiang Province, Yangzhou, Zhenjiang and Changzhou of Jiangsu Province and Chizhou of Anhui Province belong to the fourth level which score of tourism development level is among 2.6 to 3.43 , with an average score of 3.02. The total tourism income of these cities are among 61.5 billion yuan to 113.334 billion yuan, of which Taizhou is the highest (113.334 billion yuan), followed by Changzhou (95.365 billion yuan). The economy level of most of them is well and most of them have excellent tourism resources. They have lots of $4 \mathrm{~A}$ level scenic spots and above such as Tiantai Mountain and Dalu Island of Taizhou, Tianmu Lake, Chinese Dinosaur Park and Tianning Templein of Changzhou, Wuzhen, Xitang and Nanhu of Jiaxing, Huijishan and Lanting of Shaoxing, etc. In addition, the tourism organization and reception capacity of these cities are also well, the number of travel agencies of which is among 72 to 157 and the number of star hotels of which is among 31 to 87 . By virtue of the existing well economic conditions and tourism resources, the tourism development level of these cities can be greatly improved (Xu \& Lu, 2017).

5) The 5th level-Weak type of tourism development

The other nine cities belong to the fifth level-the weak type of tourism development which score are among 0.76 and 2.53, and the average score is 1.59 . The economic development level of these cities is general and the tourism resources are abundant but the quality is not high. Indicators such as the total tourism income, the number of tourists at home and abroad and others are low. In particular, Ma'anshan, Chuzhou, Tongling and other cities of Anhui Province, the advantages of tourism resources of which are not obvious and the tourist attraction of which are low, and they have not really integrated into the Yangtze River Delta regional cooperation circle. However, with the continuous improvement of 
economic level and the further increase of tourism development intensity, their development potential is undoubtedly huge.

\section{Conclusion}

Based on analytic hierarchy process and the cluster analysis, the tourism development levels of 26 cities in Yangtze River Delta are divided into five levels. The conclusions are as follows:

1) From the point of view of the total amount of GDP and the level of tourism development, the GDP ranking of the 26 cities is highly consistent with the ranking of the level of tourism development, and the level of tourism development is closely related to the level of economic development.

2) The average score of tourism development levels from the first level to the fifth level is $24.76,7.75,3.73,3.02$ and 1.59 respectively the ratio of which is about 10:3.1:1.5:1.2:0.6. It can be seen that the first level of Shanghai is far ahead of other cities and its leading position will be unshakable for a long time. Cities of the second level also have great advantages (Yu et al., 2012) and differences of cities of the third, fourth and fifth levels are relatively small.

3) According to the clustering results of tourism development level, there are obvious pyramid characteristics from the first level to the fifth level (Zhang \& Sun, 2016) which number is separately $1,3,6,7$ and 9 . Shanghai is located at the top of the pyramid, followed by Hangzhou, Suzhou and Nanjing and Ningbo and other 6 cities are in the middle. Jiaxing and other 7 cities and Yangzhou and other 9 cities are at the bottom of the pyramid.

4) In terms of geographical distribution, the level of tourism development of cities of Sea-shore, River-shore and Lake-shore is higher than that of inland cities. Except of Jinhua and Hefei, cities of the first, second and third levels are all with the characteristic of Sea-shore, River-shore and Lake-shore. The convenient land and water transportation conditions and strong economic strength are great advantages of these cities.

\section{Discussions}

In this paper, the tourism development level of 26 cities of the Yangtze River Delta is evaluated and classified by hierarchical analysis and cluster analysis. Limited by data acquisition, the index system established in the hierarchical analysis method needs to be improved. More scientific, complete and systematic evaluation index system will be established if the aspects of tourism industry scale, internationalization level, scenic area accessibility level, tourism demand level, regional support level and tourism resource level can be all concluded in the future and the conclusions will be more scientific and objective (Wang \& Ma., 2019).

\section{Conflicts of Interest}

The authors declare no conflicts of interest regarding the publication of this paper. 


\section{References}

National Development and Reform Commission, Ministry of Housing and Urban-Rural Development of the People's Republic of China (NDRC) (2016). Development Plan of the Yangtze River Delta Urban Agglomeration. https://www.ndrc.gov.cn/xxgk/zcfb/ghwb/201606/t20160603 962187.html

Zhang, Z. G., \& Jia T. F. (2005). Construction of Tourism Circle in the Yangtze River Delta Region. Human Geography, No. 2, 72-76.

Zhan, J. (2018). Study on the Economic Difference and Influencing Factors of Tourism in Yangtze River Delta Urban Agglomeration. World Geographic Studies, 27, 120-130.

Ministry of Culture and Tourism of the People's Republic of China (MCT) (2018). The Year Book of China Tourism Statistics. Beijing, China Tourism Press.

Cao, F. D., Huang, Z. F., \& Wu, J., et al. (2012). Spatial and Temporal Patterns and Structure Rationality Evaluation of Urban Tourism Competition Potential: A Case Study of the Changjiang River Delta. Scientia Geographica Sinica, 32, 944-950.

Zhang, G. H., Liu, J., \& Li, Y. C. (2013). Comprehensive Evaluation and Temporal-Spatial Evolution of the Development Level of Tourism in China's Coastal Provinces. Areal Research and Development, 32, 22-27.

Zhu, Y. G., \& Wan X. (2005). Comprehensive Assessment of International Competitiveness of Chinese Tourism Industry. Human Geography, 20, 57-61.

Liang, B. P., et al. (2004). Comprehensive Evaluation on Urban Ecosystem Suitability of Provinces in China. Urban Environment and Urban Ecology, 17, 22-24.

He, T. X. (2013). Evaluation of Tertiary System of Tourism Center in Yangtze River Delta. Urban Issues, No. 4, 36-41.

Xu, Z. Y., \& Lu, C. H. (2017). Competitiveness Evaluation of Urban Tourism Industry in Yangtze River Based on AHP Model and BP Neural Network Model. China Population, Resources and Environment, 27, 237-240.

Yu, H., Lu, L., \& Zhu, D. F. (2012). Coordination and Influencing Factors of Urban Tourism and Urban Development in Yangtze River Delta. Journal of Natural Resources, 27, 1746-1757.

Zhang, Y., \& Sun, G. N. (2016). Spatial Relation Between City Size and Tourism Growth, and Its Evolution and Driving Factors: New Understanding of City Level System in the Yangtze River Delta. Scientia Geographica Sinica, 36, 1877-1884.

Wang, H. L., \& Ma, G. Q. (2019). A Comprehensive Evaluation and Temporal-Spatial Difference Analysis of Tourist Industry Development in the Golden Section of the Silk Road. Journal of Lanzhou University (Social Science), 47, 114-121. 